This is an electronic reprint of the original article. This reprint may differ from the original in pagination and typographic detail.

Author(s): Unhjem, Astrid; Eklund, Kenneth; Nergård-Nilssen, Trude

Title: $\quad$ Early communicative gestures and play as predictors of language development in children born with and without family risk for dyslexia

Year: $\quad 2014$

Version:

Please cite the original version:

Unhjem, A., Eklund, K., \& Nergård-Nilssen, T. (2014). Early communicative gestures and play as predictors of language development in children born with and without family risk for dyslexia. Scandinavian Journal of Psychology, 55(4), 326-332.

https://doi.org/10.1111/sjop.12118

All material supplied via JYX is protected by copyright and other intellectual property rights, and duplication or sale of all or part of any of the repository collections is not permitted, except that material may be duplicated by you for your research use or educational purposes in electronic or print form. You must obtain permission for any other use. Electronic or print copies may not be offered, whether for sale or otherwise to anyone who is not an authorised user. 
Title:

Early communicative gestures and play as predictors of language development in children born with and without family risk for dyslexia

Authors:

Astrid Unhjem, University of Troms $\varnothing$, Norway

Kenneth Eklund, University of Jyväskylä, Finland

Trude Nergård-Nilssen, University of Troms $\emptyset$, Norway 


\section{Early communicative gestures and play as predictors of language development in children born with and without family risk for dyslexia}

The present study investigated early communicative gestures, play, and language skills in children born with family risk for dyslexia (FR) and a control group of children without this inheritable risk at ages 12, 15, 18, and 24 months. Participants were drawn from the Troms $\varnothing$ Longitudinal Study of Dyslexia (TLD) which follows children's cognitive and language development from age 12 months through Grade 2 in order to identify early markers of developmental dyslexia. Results showed that symbolic play and parent reported play at age 12 months and communicative gestures at age 15 months explained $61 \%$ of the variance in productive language at 24 months in the FR group. These early nonlinguistic measures seem to be potentially interesting markers of later language development in children born at risk for dyslexia.

\section{Introduction}

Dyslexia can be described as an inheritable, specific, and language based learning disability, characterized by poor decoding and spelling (Gallagher, Frith, \& Snowling, 2000; Lyon, Shaywitz, \& Shaywitz, 2003; H. Lyytinen et al., 2004). Accumulated findings show that phonological deficits are a proximate cause of the reading impairments seen in individuals with dyslexia (Caylak, 2010; Hulme \& Snowling, 2009). Longitudinal studies of children born at family risk for dyslexia have shown that FR children perform significantly worse than controls on speech perception at the age of 6 months (Richardson, Leppänen, Leiwo, \& Lyytinen, 2003), and on phonological awareness from 3 years of age (Gallagher et al., 2000; H. Lyytinen et al., 2004; van Alphen et al., 2004). Numerous studies show that early phonological skills are salient predictors of later reading skills (Carroll, Snowling, Stevenson, \& Hulme, 2003; H. 
Lyytinen et al., 2004; Scarborough, 1990). Snowling (2008) suggests, however, that phonological deficits are not sufficient to explain FR children's literacy outcomes. Broader language skills such as maximum sentence length and receptive and expressive language have indeed been found to explain variance in emergent literacy (Scarborough, 1990; Snowling, Gallagher, \& Frith, 2003; Torppa, Lyytinen, Erskine, Eklund, \& Lyytinen, 2010). Thus, broader language delays are likely to increase the risk of later reading difficulties in FR children.

The present study aimed to investigate predictors of broader language skills in FR and control children from age 12 to 24 months. The language development is in this period driven by an interplay between cognitive development and vocabulary growth (Waxman \& Leddon, 2011), in which vocabulary growth in turn depends on the interaction between phonological and lexical development (Stoel-Gammon, 2011; Walley, 1993). Children with no family risk for dyslexia who lag behind in language development at age 2 typically catch up with their peers later (Bloom, 1993). In contrast, early language delays in FR children seem to persist (P. Lyytinen, Poikkeus, Laakso, Eklund, \& Lyytinen, 2001). These differences urge for a closer examination of the skills underpinning language at the age of 2 in FR and no-FR children.

Gestures and play are considered to be closely related to language development in the child's second year of life through the development of mental representations (Capirci \& Volterra, 2008; McCune, 2008). Mental representations can be described as a cognitive process whereby children store information from their experiences, which in turn enable them to symbolize and express their knowledge in gestures, play and language (McCune, 1995). Several studies have demonstrated strong associations between early gestures and play and later language skills (e.g., Caselli, Rinaldi, Stefani, and Volterra, 2012; Tamis-LeMonda and Bornstein, 1993). However, to our knowledge 
the nature of these relationships in FR children remains largely unexplored in research literature. The current study seeks to at least partially fill this void.

Children's first communicative gestures are typically produced before the age of 10 months, and are closely related to vocabulary growth in in the single word period. Combinations of gestures and single words typically precede two-word combinations (Capirci, Iverson, Pizzuto, \& Volterra, 1996; Caselli, Rinaldi, Stefanini, \& Volterra, 2012; Iverson \& Goldin-Meadow, 2005). Moreover, Rowe and Goldin-Meadow (2009) found that gestures at 18 months predict language skills at 42 months. According to those studies, early communicative gestures reflect children's potential for language learning in their developing mental representations. Furthermore, gestures facilitate communication and language development by giving the child the opportunity to communicate meanings beyond what they are able to express in speech and to engage in episodes of joint attention. The frequency and quality of joint attention with caregivers are found to be closely related to children's early language development (Laakso, Poikkeus, Katajamäki, \& Lyytinen, 1999; Rowe \& Goldin-Meadow, 2009; Tamis LeMonda, Bornstein, \& Baumwell, 2001).

Several studies have demonstrated concurrent and predictive relations between symbolic play and language skills between ages 13 to 42 months (P. Lyytinen et al., 2001; Tamis-LeMonda \& Bornstein, 1990, 1993; Ungerer \& Sigman, 1984). However, Tamis-LeMonda and Bornstein (1993) suggest that these relations are specific to certain levels of play and language, and that they change with age. McCune (1995) found that play developed orderly from pre-symbolic (functional), to single pretend (symbolic), then to combinatorial pretend, and finally to hierarchical pretend play. Language development followed similar patterns in structural transitions. However, in some children there was a delay between the occurrence of certain levels of play and 
corresponding language transitions. McCune and Vihman (2001) argue that this delay could be explained by a lack in the phonetic repertoire seen in these children. Interestingly, Richardson et al. (2003) found deficits in speech perception in FRchildren as early as at 6 months of age. Deficits in speech perception could precede a lack in the phonetic skills, and inhibit vocabulary growth. Therefore, it is interesting to speculate that FR children have an increased risk for a mismatch between development of play and following language transitions.

The Jyväskylä Longitudinal Study of Dyslexia (JLD) is so far the only study that has investigated the relations between play and language development in FR children. The Finnish study failed to find significant differences between the FR group and the control group in symbolic play at ages 14 and 18 months. However, the JLD study found more and stronger correlations between symbolic play at 14 months and language skills at 24, 30, and 42 months, respectively, in the control group compared to the FR group (P. Lyytinen et al., 2001). In the present study we addressed these findings by employing the same test as the JLD study and by following children from a younger age (12 months). We added parent-reported play in home context to get a more comprehensive measure of play, and included early gestures as a supplementary measure of children's mental representations and non-linguistic communication.

The present study was undertaken to explore the predictive relations of early gestures and play with later language skills, and to compare the FR group and the control group on these matters. The study was guided by three research questions: (1) Do the FR and the control group differ in terms of early gestures, play, and language at ages 12, 15, 18 and 24 months? We hypothesized that there would be no significant differences between the FR and the control on these measures. (2) Do gestures and play at ages 12,15 and 18 months, respectively, correlate with productive and receptive 
language skills at 24 months, and are there any potential between-group differences? We anticipated that we would find correlations between early measures of gestures and play with both productive and receptive language outcomes at the age of 24 months, and that these correlations could turn out to be stronger within the control group. (3) To what extent do skills in early gestures and play predict variations in language skills at 24 months in FR and control children, respectively? Here, we hypothesized that we would see differences between functional and symbolic play and gestures at 12, 15 and 18 months, respectively, in predictive relations to language skills at 24 months, and that we would find a difference between the control and the FR group.

\section{Method}

\section{Participants}

The 53 children reported here were drawn from the Troms $\varnothing$ Longitudinal study of Dyslexia (TLD). Full term babies who had monolingual Norwegian parents, no known sensory impairment or neurological developmental disorders were invited to participate in the study.

The children were selected through a three-stage procedure: In stage 1, parents were asked to complete a short questionnaire that included questions concerning difficulties in learning to read or spell among themselves and their close relatives. In stage 2, parents were invited to a semi-structured interview, dealing with questions concerning demographic and socioeconomic conditions, the occurrence of reading and writing difficulties during childhood and adulthood, and reading and writing difficulties among close relatives. In stage 3 , all parents were tested on a wide battery of reading and spelling tests. Also, all parents were tested with Wechsler Abbreviated Scale of Intelligence (Wechsler, 1999; Ørbeck \& Sundet, 2007), using the four-subtest format. 
Children were assigned to the family risk group when two of the following three criteria were met: At least one of the parents had self-reported reading impairments, and/or reported to have a close relative with reading disorders, and/or scored below the 15 th percentile on a nonword reading fluency test. Thirty-two children met the selection criteria for the FR group (12 girls, 20 boys). Children whose parents achieved a test score above the 15 th percentile, and who reported no reading impairments and no reading disorders in close relatives were assigned to the control group. Twenty-one children met the selection criteria for the control group ( 8 girls and 13 boys). There were no group differences among the parents in general cognitive abilities: parents in the FR group achieved a full IQ score of $M=117.45(S D=9.51)$ whereas parents in the control group achieved a full IQ score of $M=118.89(S D=11.60), F(1,71)=0.24, p=$ .623 .

\section{General procedure}

A repeated measures design was used in which children were seen at ages 12, 15, 18 and 24 months, within \pm 3 weeks (see Table 1 ). All children were tested individually in a laboratory at the university. Each session lasted 1-2 hours and was carried out with both the examiner and one parent in the room. Sessions were videotaped for later analyses. Parents received and completed a parental checklist of their child's receptive and expressive vocabulary a day or two before the visit to the university lab.

\section{Measures}

\section{Early gestures.}

The Norwegian adaption of the MacArthur-Bates Communicative Development Inventories (MCDI - Words and Gestures), part II: “Actions and Gestures” was used to 
assess early communicative gestures (Kristoffersen \& Simonsen, 2012). Items marked "yes" in subtest (1) First communicative gestures were summed to yield the early gestures score (maximum score of 12). Chronbach's alpha coefficient for internal consistency reliability for part II as a whole is reported to be .90

Play.

Parent reported play was measured by MCDI - Words and Gestures, part II. Items marked "yes" in the following subtests: (3) Actions with objects, (4) Pretending to be a parent, and (5) Imitating other adult actions, were summed to yield the play score (maximum score of 45).

Children's solitary play was assessed by using an adaption of the Symbolic Play Test (SPT) by Lowe and Costello (1988). In the present study, three out of the original four toy sets were used (set I, set II and set IV). SPT was administered and coded according to the guidelines of the manual (Lowe \& Costello, 1988). The child's play behavior was videotaped and coded afterwards.

The scoring was based on directly observed behavior units, where the child's intention was more important than the execution of the actions. From the children's play behavior 25 different items were scored; 11 items from set I, 6 items from set II, and 8 items from set IV. Items labelled as functional play included meaningful combinations of objects but with little sense of symbolic activity, e.g. putting the spoon into the cup. Symbolic play items included meaningful use of objects in combination with self- or other-directed symbolic activity, e.g. feeding the doll (Casby, 2003; P. Lyytinen, Laakso, Poikkeus, \& Rita, 1999). In line with McCune (1995) play was divided into episodes. The symbolic play score was defined as the total number of symbolic play episodes that the child performed with the play sets, and the functional play score was defined as the total number of functional play episodes. Inter-observer reliability was 
assessed by having two persons coding $18 \%$ of the cases. Pearson's correlations between the coders were .87 for functional play, and .89 for symbolic play.

\section{Productive and receptive language skills.}

The Norwegian adaption of the MacArthur-Bates Communicative Development Inventories, MCDI - Words and Sentences, (Kristoffersen \& Simonsen, 2012) and the Bayley Scales of Infant Development, 3rd edition, BSID-III, (Bayley, 2006), were used to assess expressive and receptive languages skills at the age of 24 months.

The MCDI - Words and Sentences, part I: "Words Children Use" contains a vocabulary checklist with 731 items divided into 22 semantic categories. Items marked as "spoken" by the parents were summed to yield the words produced score.

Chronbach's alpha coefficient for internal consistency reliability is reported to be .99 (Kristoffersen, Simonsen, Eiesland, \& Henriksen, 2012).

The language scale of BSID-III consists of two subtests. The Expressive communication subtest assesses the child's ability to vocalize, communicate with others, picture naming, and morpho-syntactic skills such as use of two-word utterances. The Receptive communication subtest includes assessments of receptive vocabulary, and the ability to understand and follow verbal instructions. Average reliability (Chronbach's alpha) for the language scales are .93 according to the manual.

\section{Results}

Table 2 shows descriptive statistics and group comparisons. As can be seen, the independent sample's T-tests showed no group differences on play, early gestures or language measures. Similarly, there were no differences between groups in terms of variance, except on gestures at age 15 months where the FR group variance was found to be larger. Effect sizes estimated with Cohen's d were small in in all other measures 
except functional play at 12 months and play at 12, 15, and 18 months, where they were moderate.

In Tables $3 \mathrm{a}$ and $\mathrm{b}$, correlation coefficients between gestures, play, and language measures are presented separately for the control and the FR group, respectively. In the control group only one significant relationship was found between early measures and later language: the correlation between symbolic play at age 12 months and expressive communication at 24 months (.49). In the FR group, on the other hand, there were several predictive correlations between gestures and play and later productive language skills at 24 months: Symbolic play at 12 months correlated significantly with both words produced and expressive communication (.60 and .52 , respectively). In addition, correlations between symbolic play at 15 months and words produced (.37) as well as symbolic play at 18 months and expressive communication (.37) were significant. Also the parent-reported play and early gestures had significant correlations to language measures in the FR group. Play at 18 months and gestures at 12 and 15 months, respectively, correlated significantly with both productive language measures (words produced, .49-.65 and expressive communication, .37-.44). In addition, play at 12 months and early gestures at 18 months correlated significantly with words produced at 24 months (.39 and .51 , respectively). The only significant correlation with receptive communication at 24 months was symbolic play at 12 months (.44).

Next, differences in the population correlation coefficients between the FR and control groups were tested using the Difference test based on Fisher's z-transformed correlation coefficients (McNemar, 1969). The predictive associations to words produced at 24 months were larger in the FR than in the control group in several early measures: Symbolic play at 15 months (.37 vs. -.16), play at 12 months (.39 vs. -.10), and early gestures at 15 months (.65 vs. .16). In line with this, symbolic play at 18 
months correlated more strongly with expressive communication in the FR group than in the control group (.37 vs. -.16).

Finally, to study the predictive power of the early measures of gestures and play to productive language and receptive language, respectively, hierarchical regression analyses were performed separately for the FR and control groups. At each of the three steps all predictors (functional play, symbolic play, play, and early gestures) from one age $(12,15$, and 18 months, respectively) were added using STEPWISE method to see which of the measures have additional significant predictive power after measure(s) of the previous age(s). The arithmetic mean of the standardized values of the expressive communication and words produced was used as the dependent outcome measure of productive language. Respectively, the receptive communication measure was used as the dependent outcome measure for receptive language.

Table 4 shows summary of hierarchical regression analysis for predicting productive and receptive language at 2 years of age in children at family risk of dyslexia only. Within the control group, none of the early measures of play and communicative gestures obtained significant predictive correlations with productive or receptive language at age 24 months. In the FR group, on the other hand, symbolic play and parent-reported play at 12 months together with early gestures at 15 months explained $61 \%$ of the variance in productive language at 24 months $(\mathrm{F}(3,23)=11.93, \mathrm{p}<.001)$. At age 12 months symbolic play was the best predictor explaining $36 \%$ of the variance of productive language. Play from the same age added the explanatory power with $11 \%$ and early gestures at 15 months with $14 \%$. In the FR group symbolic play at 12 months was the only significant predictor of receptive language at 24 months explaining $19.1 \%$ of its variance $(\mathrm{F}(1,25)=5.92, \mathrm{p}<.05)$.

\section{Discussion}


The present study examined early development of communicative gestures and play and their predictive relations to language outcomes at age 24 months in a group of FR children and a control group. As expected, no significant group differences were found in measures of play at ages 12,15 , or 18 months or in language skills at 24 months. These results are in line with previous findings of P. Lyytinen et al. (2001). There were, however, moderate effect sizes and approximately $30 \%$ non-overlap in the distributions between the two groups on parent reported play at 12, 15, and 18 months. With larger sample sizes this would probably have yielded significant between-group differences in which the FR group performed worse. These novel findings on possible group differences in parent reported play are interesting, but needs to be studied further in larger groups.

Early gestures at ages 12,15 and 18 months correlated with measures of productive language at 24 months in the FR group. This is in line with previous research on typically developing children (Capirci et al., 1996; Caselli et al., 2012; Iverson \& Goldin-Meadow, 2005). Surprisingly, relations between early gestures and later productive language skills in the control group, although being positive were not significant. This could be due to small sample size decreasing the statistical power. Besides, the variance in early gestures was smaller in the control group compared to the FR group at 15 months and the distribution slightly skewed at 18 months suggesting that the measures of early gestures did not optimally tap the skills of children in the control group. Notwithstanding this, our results indicate a stronger relationship between early gestures and later language skills within the FR-than within the control group.

We found no significant predictive relations between early gestures and receptive communication at 24 months in either group. Our results thus contrast the findings by Caselli et al. (2012) that early gestures correlated stronger with word 
comprehension than with word production at 18 months, and with the findings by Rowe and Goldin-Meadow (2009) that gesture vocabulary at 18 months predicted receptive vocabulary at 42 months. However, the contradictory findings could be due to the different measures employed: Whereas the Caselli et al. (2012) and the Rowe and Goldin-Meadow (2009) studies, respectively, tapped skills in receptive vocabulary, our study tapped skills in receptive communication, including the ability to understand and follow verbal instructions. Our results thus indicate that early gestures are less related to general receptive language skills than to receptive vocabulary.

The present study found that symbolic, but not functional, play correlated with later language measures. In the FR group, symbolic play at age 12 months correlated significantly with word production, expressive communication, and receptive communication at age 24 months. In the control group, on the other hand, symbolic play correlated significantly only with expressive communication. The latter findings converge well with previous findings on the relationship between symbolic play at 1314 months and language skills at 20-24 months in typically developing children (P. Lyytinen et al., 1999; Tamis-LeMonda \& Bornstein, 1993; Ungerer \& Sigman, 1984). The present study adds to the previous findings by demonstrating that the relationship between symbolic play and language skills is found as early as at age 12 months in both FR children and typically children. The results showed, however, that the correlations between play at 15 and 18 months, respectively, and language skills at 24 months were weaker, and that they only related to expressive language. Similarly, P. Lyytinen et al. (1999) found that symbolic play at 14 months, but not at 18 months, predicted language outcomes at 24 months. Taken together, play competence at ages between 12 and 15 months seems to be at its best for predicting later language skills. One possible explanation to this could be that in the developmental interplay between cognitive 
development and vocabulary growth (Waxman \& Leddon, 2011), vocabulary growth gradually provides a stronger contribution to general language development than mental representations as indexed by symbolic play.

In contrast to the Finnish study (P. Lyytinen et al., 2001), we found more and stronger predictive correlations between symbolic play at ages 12,15 and 18 months, and language skills at 24 months in the FR group compared to the control group. The contradictory findings could partly be due to the small size of the control group in the present study. However, the sample size cannot explain the systematic between-group differences in predictive correlations found in the present study. Symbolic play, particularly at 12 months, and early communicative gestures seems to be stronger predictors of language outcomes at 24 months in the FR group than in the control group. This finding suggests a more stable variation within the FR group than in the control group in terms of mental representations and nonlinguistic communicative skills that are crucial to language development. Perhaps we here see the outline of two subgroups within the FR group identified in earlier longitudinal studies of dyslexia: those who will develop good language skills and thus carry less risk for developing reading impairments, and those who will develop poor language skills and thus carry greater risks for later reading impairments (Gallagher et al., 2000; Torppa et al., 2007).

An important finding in the present study was that symbolic play and parentreported play at 12 months together with early gestures at 15 months explained $61 \%$ of the variance in productive language at age 24 months in the FR group. We also found that symbolic play explained $19.1 \%$ of the variance in receptive language. Put another way, our study found that children's early repertoire of mental representations as well as their ability to express their knowledge and engage in communication and joint 
attention are strong predictors of language outcomes at age 2 years in children born at familial risk for dyslexia.

It is a general view that most FR children display phonological deficits, detectable already from the age of 6 months (Richardson et al., 2003). According to McCune (1995) a lack in phonetic repertoire could reduce the correspondence between developmental transitions in play and language. Thus, we expected that these relations could be less salient in the FR group compared to controls. Our study found that this was not the case. Although we did not measure phonological skills or auditory perception, our results indicate that the phonological deficits many of the children in the FR group can be assumed to share seem not to interfere with their earliest vocabulary development. Possible explanations are that children's first words are stored as holistic units (Walley, 1993), based on a limited and rather individual consonant repertoire in each child (McCune \& Vihman, 2001). Thus, FR children's earliest language development, before vocabulary growth spurt, might not be considerably influenced by their possible deficiencies in phonological processing.

To our knowledge, the present study is the first to show the strong influence from early gestures and play from age 12 months in FR children. These novel findings need however to be replicated in future studies employing larger samples. Our findings indicate that well-developed, early mental representations and nonlinguistic communicative skills act as a catalyst for FR children's language skills at age 2. These findings are important for both theoretical and clinical reasons: Previous studies have shown that language skills at 24 months are strongly related to later language skills, and that late talkers who are born at risk for dyslexia are less likely to catch up with their peers in contrast to late talkers without this risk (P. Lyytinen, Eklund, \& Lyytinen, 2005). 
To conclude, early gestures and symbolic play seem to act as potentially interesting markers of later language difficulties in the case when children have a familial risk for dyslexia However, the current findings leave open the question of whether the present family-risk children, who appear to have well-developed mental representations, will go on to develop skills that protect them from later reading impairments - and vice versa. The predictive validity of these non-linguistic markers will be evaluated in few years, that is, once it is possible to examine the differences between FR children with and without dyslexia and controls.

\section{Acknowledgements}

This study was supported by a grant from the Troms $\varnothing$ Research Foundation to the third author of the paper. We thank all families who took part in the study.

\section{References}

Bayley, N. (2006). Bayley Scales of Infant and Toddler Development (3rd Edition). San Antonio: TX-Harcourt assessment.

Bloom, L. (1993). The transition from infancy to language: acquiring the power of expression. Cambridge: Cambridge University Press.

Capirci, O., Iverson, J. M., Pizzuto, E., \& Volterra, V. (1996). Gestures and words during the transition to two-word speech. Journal of child language, 23, 645-674.

Capirci, O., \& Volterra, V. (2008). Gesture and speech The emergence and development of a strong and changing partnership. Gesture, 8(1), 22-44.

Carroll, J. M., Snowling, M. J., Stevenson, J., \& Hulme, C. (2003). The development of phonological awareness in preschool children. Developmental Psychology, 39(5), 913.

Casby, M. W. (2003). The development of play in infants, toddlers, and young children. Communication Disorders Quarterly, 24(4), 163-174.

Caselli, M. C., Rinaldi, P., Stefanini, S., \& Volterra, V. (2012). Early Action and Gesture "Vocabulary" and Its Relation With Word Comprehension and Production. Child development, 83(2), 526-542.

Caylak, E. (2010). The studies about phonological deficit theory in children with developmental dyslexia: review. American Journal of Neuroscience, 1(1), 1-12.

Gallagher, A., Frith, U., \& Snowling, M. J. (2000). Precursors of literacy delay among children at genetic risk of dyslexia. Journal of Child Psychology and Psychiatry, 41(2), 203-213.

Hulme, C., \& Snowling, M. J. (2009). Developmental Disorders of Language Learning and Cognition: Wiley-Blackwell.

Iverson, J. M ., \& Goldin-M eadow, S. (2005). Gesture paves the way for language development. Psychological Science, 16(5), 367-371.

Kristoffersen, K. E., \& Simonsen, H. G. (2012). Tidlig språkutvikling hos norske barn : MacArthur-Bates foreldrerapport for kommunikativ utvikling. Oslo: Novus. 
Kristoffersen, K. E., Simonsen, H. G., Eiesland, E. A., \& Henriksen, L. Y. (2012). Utvikling og variasjon i kommunikative ferdigheter hos barn som lærer norsk - en CDI-basert studie. Norsk tidsskrift for logopedi(12), 34-43.

Laakso, M .-L., Poikkeus, A.-M ., Katajamäki, J., \& Lyytinen, P. (1999). Early intentional communication as a predictor of language development in young toddlers. First Language, 19(56), 207-231.

Lowe, M., \& Costello, A. J. (1988). Symbolic play test. Second edition. M anual. London: GL Assessment.

Lyon, G. R., Shaywitz, S. E., \& Shaywitz, B. A. (2003). Defining dyslexia, comorbidity, teacher's knowledge of language and reading. Annals of Dyslexia, 53(1), 1-14.

Lyytinen, H., Ahonen, T., Eklund, K., Guttorm, T., Kulju, P., Laakso, M.-L., . . . Viholainen, H. (2004). Early development of children at familial risk for Dyslexia-follow up from birth to school age. Dyslexia, 10(3), 146-178.

Lyytinen, P., Eklund, K., \& Lyytinen, H. (2005). Language development and literacy skills in latetalking toddlers with and without familial risk for dyslexia. Annals of Dyslexia, 55(2), 166-192.

Lyytinen, P., Laakso, M.-L., Poikkeus, A.-M ., \& Rita, N. (1999). The development and predictive relations of play and language across the second year. Scandinavian Journal of Psychology, 40(3), 177-186.

Lyytinen, P., Poikkeus, A.-M., Laakso, M.-L., Eklund, K., \& Lyytinen, H. (2001). Language development and symbolic play in children with and without familial risk for dyslexia. Journal of Speech, Language, and Hearing Research, 44(4), 873-885.

M cCune, L. (1995). A Normative Study of Representational Play at the Transition to Language. Developmental Psychology, 31(2), 198-206.

McCune, L. (2008). How children learn to learn language: Oxford University Press.

M cCune, L., \& Vihman, M. M. (2001). Early phonetic and lexical development: A productivity approach. Journal of Speech, Language and Hearing Research, 44(3), 670.

M cNemar, Q. (1969). Psychological statistics (fourth edition). New York - London - Sydney Toronto: John Wiley and Sons, Inc.

Richardson, U., Leppänen, P. H. T., Leiwo, M ., \& Lyytinen, H. (2003). Speech perception of infants with high familial risk for dyslexia differ at the age of 6 months. Developmental Neuropsychology, 23(3), 385-397.

Rowe, M. L., \& Goldin-M eadow, S. (2009). Early gesture selectively predicts later language learning. Developmental science, 12(1), 182-187.

Scarborough, H. S. (1990). Very early language deficits in dyslexic children. Child development, 61(6), 1728-1743.

Snowling, M. J. (2008). Specific disorders and broader phenotypes: The case of dyslexia. The Quarterly Journal of Experimental Psychology, 61(1), 142-156.

Snowling, M. J., Gallagher, A., \& Frith, U. (2003). Family risk of dyslexia is continuous: Individual differences in the precursors of reading skill. Child development, 74(2), 358-373.

Stoel-Gammon, C. (2011). Relationships between lexical and phonological development in young children*. Journal of child language, 38(01), 1-34.

Tamis-LeM onda, C. S., \& Bornstein, M. H. (1990). Language, play, and attention at one year* 1. Infant Behavior and Development, 13(1), 85-98.

Tamis-LeM onda, C. S., \& Bornstein, M. H. (1993). Play and its relations to other mental functions in the child. In M. H. Bornstein \& A. W. O'Reilly (Eds.), The role of play in the development of thought. San Fransisco: Josey-Bass Publishers.

Tamis LeM onda, C. S., Bornstein, M. H., \& Baumwell, L. (2001). M aternal responsiveness and children's achievement of language milestones. Child development, 72(3), 748-767.

Torppa, M., Lyytinen, P., Erskine, J., Eklund, K., \& Lyytinen, H. (2010). Language development, literacy skills, and predictive connections to reading in Finnish children with and without familial risk for dyslexia. Journal of learning disabilities, 43(4), 308-321. 
Torppa, M., Tolvanen, A., Poikkeus, A.-M ., Eklund, K., Lerkkanen, M .-K., Leskinen, E., \& Lyytinen, H. (2007). Reading development subtypes and their early characteristics. Annals of Dyslexia, 57(1), 3-32.

Ungerer, J. A., \& Sigman, M. (1984). The relation of play and sensorimotor behavior to language in the second year. Child development, 55(4), 1448-1455.

van Alphen, P., de Bree, E., Gerrits, E., de Jong, J., Wilsenach, C., \& Wijnen, F. (2004). Early language development in children with a genetic risk of dyslexia. Dyslexia, 10(4), 265288.

Walley, A. C. (1993). The role of vocabulary development in children's spoken word recognition and segmentation ability. Developmental Review, 13(3), 286-350.

Waxman, S. R., \& Leddon, E. M. (2011). Early Word-Learning and conceptual development. In U. Goswami (Ed.), The Wiley-Blackwell Handbook of Childhood Cognitive Development. Second edition. (pp. 180-208): Wiley-Blacwell.

Wechsler, D. (1999). Wechsler Abbreviated Scale of Intelligence. New York: The Psychological Corporation: Harcourt Brace $\&$ Company.

Ørbeck, B. \& \& Sundet, K. (2007). WASI (Wechsler Abbreviated Scale of Intelligence) Norsk versjon M anualsupplement. Stockholm: Harcort Asessment Inc. 
Table 1. Overview over screening procedures

\begin{tabular}{|c|c|c|c|c|c|c|}
\hline Variable & Instrument & Setting & \multicolumn{4}{|c|}{ Age } \\
\hline Play & MCDI (WG) & Parent report & $x$ & $x$ & $x$ & \\
\hline Functional play & SPT & Lab. & $x$ & $x$ & $x$ & \\
\hline Words produced & MCDI (WS) & Parent report & & & & $x$ \\
\hline Expressive communication & Bayley III (BSID) & Lab. & & & & $x$ \\
\hline Receptive communication & Bayley III (BSID) & Lab. & & & & $x$ \\
\hline
\end{tabular}

Note. M CDI (WG) = M acArthur Communicative Development Inventory - Words and Gestures. MCDI (WS) =M McArthur Communicative Development Inventory - Words and Sentences. SPT =Symbolic Play Test. Bayley III (BSID) =The Bayley Scales of Infant Development, 3rd edition. Lab. =laboratory. 
Table 2. Descriptive statistics and group comparisons

\begin{tabular}{|c|c|c|c|c|c|c|c|}
\hline \multirow[b]{2}{*}{ Variable } & \multirow[b]{2}{*}{ Range } & \multicolumn{2}{|c|}{ FR group $^{\text {a) }}$} & \multicolumn{2}{|c|}{ Control group $^{\text {a) }}$} & \multirow[b]{2}{*}{$t^{b)}$} & \multirow{2}{*}{$\begin{array}{l}\text { Effect } \\
\text { size }^{c)}\end{array}$} \\
\hline & & Mean & SD & Mean & SD & & \\
\hline \multicolumn{8}{|l|}{ Early gestures } \\
\hline 12 months & $0-10$ & 6.59 & 2.37 & 6.45 & 2.32 & -.20 & 0.06 \\
\hline 15 months & $8-11$ & 8.63 & 1.50 & 9.00 & 1.10 & 1.05 & -0.29 \\
\hline 18 months & $7-12$ & 9.53 & 1.34 & 9.95 & 1.20 & 1.16 & -0.33 \\
\hline \multicolumn{8}{|l|}{ Play } \\
\hline 12 months & $0-30$ & 9.45 & 5.58 & 11.80 & 7.44 & 1.26 & -0.36 \\
\hline 15 months & $7-35$ & 20.06 & 6.92 & 23.19 & 5.69 & 1.72 & -0.49 \\
\hline 18 months & $13-41$ & 26.44 & 6.31 & 29.86 & 6.91 & 1.86 & -0.52 \\
\hline \multicolumn{8}{|c|}{ Functional play } \\
\hline 12 months & $0-22$ & 6.14 & 5.71 & 3.90 & 3.96 & -1.51 & 0.46 \\
\hline 15 months & $1-23$ & 10.35 & 5.16 & 9.14 & 5.48 & -.81 & 0.23 \\
\hline 18 months & $2-23$ & 12.71 & 4.91 & 11.20 & 5.54 & -1.02 & 0.29 \\
\hline
\end{tabular}


Symbolic play

$\begin{array}{lccccccc}12 \text { months } & 0-15 & 3.32 & 3.80 & 2.80 & 2.82 & -.52 & 0.16 \\ 15 \text { months } & 0-22 & 8.65 & 5.61 & 8.62 & 4.53 & -.02 & 0.01 \\ 18 \text { months } & 0-29 & 11.13 & 6.11 & 13.10 & 6.25 & 1.12 & -0.32\end{array}$

Productive language, 24 months

\section{Words}

produced

$12-732$

$259.06 \quad 176.34$

$228.67 \quad 141.62$

$-.66$

0.19

Expressive

communication

$23-37$

31.50

3.93

31.71

4.29

$.19-0.05$

Receptive language, 24 months

Receptive

$\begin{array}{llllllll}\text { communication } & 19-30 & 25.03 & 2.76 & 25.14 & 2.74 & .89 & 0.04\end{array}$

Note. ${ }^{\text {a) }}$ Number of subjects varied due to missing data in single measures: the FR group, $\mathrm{n}=28-32$ and the control group, $\mathrm{n}=20-21 .{ }^{\mathrm{b})}$ All group comparisons were non-significant, $\mathrm{p}>.05$. $^{\mathrm{c})}$ Effect sizes were estimated with Cohen's d computed using pooled standard deviation. 
Table 3a. Correlations between early communicative gestures, play, and language measures in the control group ${ }^{a}$

\begin{tabular}{|c|c|c|c|c|c|c|c|c|c|c|c|c|c|c|}
\hline & & & & & & & & & & & & \multicolumn{2}{|c|}{ Prod. lang. } & \multirow{3}{*}{$\begin{array}{l}\text { Rec. lang. } \\
\text { BSID } \\
24 \mathrm{~m}\end{array}$} \\
\hline & \multicolumn{2}{|c|}{ Early gestures } & \multicolumn{3}{|c|}{ Play } & \multicolumn{3}{|c|}{ Functional Play } & \multicolumn{3}{|c|}{ Symbolic play } & \multirow{2}{*}{$\begin{array}{l}\text { CDI } \\
24 \mathrm{~m}\end{array}$} & \multirow{2}{*}{$\begin{array}{l}\text { BSID } \\
24 \mathrm{~m}\end{array}$} & \\
\hline & $15 \mathrm{~m}$ & $18 \mathrm{~m}$ & $12 \mathrm{~m}$ & $15 \mathrm{~m}$ & $18 \mathrm{~m}$ & $12 \mathrm{~m}$ & $15 \mathrm{~m}$ & $18 \mathrm{~m}$ & $12 \mathrm{~m}$ & $15 \mathrm{~m}$ & $18 \mathrm{~m}$ & & & \\
\hline \multicolumn{15}{|c|}{ Early gestures } \\
\hline 12 months & .18 & .03 & .19 & .21 & .10 & .34 & $.57 * *$ & .22 & .16 & .05 & -.05 & .36 & .24 & .29 \\
\hline 15 months & & .38 & .43 & .26 & .27 & .34 & .07 & $.52 *$ & .38 & .13 & .07 & .16 & .08 & .17 \\
\hline 18 months & & & $.53^{*}$ & .20 & .37 & .07 & -.10 & -.04 & .39 & -.00 & .32 & .29 & .19 & -.03 \\
\hline \multicolumn{15}{|l|}{ Play } \\
\hline 12 months & & & & $.56^{*}$ & .34 & $.53 *$ & .23 & .27 & -.28 & -.31 & -.35 & -.10 & -.12 & -.12 \\
\hline 15 months & & & & & $.69 * * *$ & .22 & .32 & .37 & .43 & $.49 *$ & .24 & .01 & -.12 & .02 \\
\hline 18 months & & & & & & -.01 & .16 & .17 & -.03 & $.54 *$ & .39 & .25 & .06 & .14 \\
\hline \multicolumn{15}{|c|}{ Functional play } \\
\hline 12 months & & & & & & & .26 & .09 & -.05 & $.48 *$ & .17 & .04 & -.04 & -.15 \\
\hline
\end{tabular}


15 months

18 months

Symbolic play

\section{2 months}

15 months

18 months

Productive language, 24 months

CDI

BSID

$\begin{array}{rrrrrrr}-.02 & -.06 & .49 * & .32 & -.06 & -.20 & -.10 \\ & .08 & .33 & .16 & .37 & .21 & .13\end{array}$

$\begin{array}{rrrrr}-.01 & -.11 & .34 & .49 * & .36 \\ & .35 & \mathbf{- . 1 6} & -.33 & -.10 \\ & & -.11 & -.16 & -.15\end{array}$

$.83 * * * \quad .50 *$

Note. Correlation coefficients, which were different in the FR and control group according to difference test based on Fisher's z-transformed correlation coefficients (McNemar, 1969), are marked with bold.

a) Number of subjects varied due to missing data in single measures: $n=19-21$. 
Table 3b. Correlations between early communicative gestures, play, and language measures in the FR group ${ }^{a}$

Prod. lang. Rec. lang.

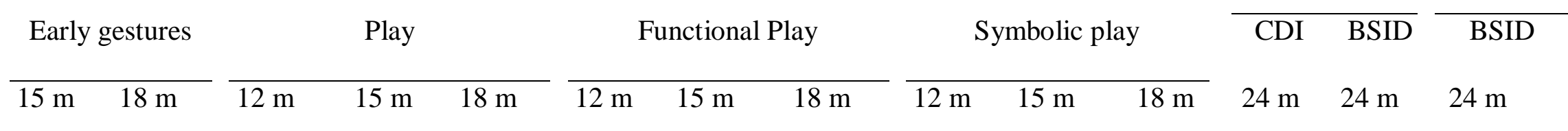

Early gestures

\begin{tabular}{|c|c|c|c|c|c|c|c|c|c|c|c|c|c|c|}
\hline 12 months & $.50 * *$ & $.40^{*}$ & $.55^{* *}$ & .32 & .31 & $.39 *$ & .09 & -.02 & .27 & .25 & .17 & $.42^{*}$ & $.38^{*}$ & .20 \\
\hline 15 months & & $.55^{* *}$ & .29 & $.42 *$ & $.47 * *$ & .05 & -.04 & .07 & -.04 & .23 & .25 & $.65 * * *$ & $.44^{*}$ & -.12 \\
\hline 18 months & & & $.56^{* *} *$ & $.41 *$ & $.53 * *$ & .11 & .16 & -.08 & .14 & .32 & .23 & $.51^{*}$ & .25 & -.17 \\
\hline
\end{tabular}

Play

\begin{tabular}{|c|c|c|c|c|c|c|c|c|c|c|c|}
\hline 12 months & $.50 * *$ & $.40 *$ & .34 & -.15 & -.03 & .09 & -.08 & .21 & $.39 *$ & .32 & .12 \\
\hline 15 months & & $.72 * * *$ & .30 & $.41 *$ & .32 & .16 & .34 & .28 & .28 & .29 & .10 \\
\hline 18 months & & & -.14 & .16 & .07 & .18 & $.40 *$ & $.43^{*}$ & $.49 * *$ & $.37 *$ & .13 \\
\hline
\end{tabular}

Functional play

12 months

\begin{tabular}{|c|c|c|c|c|c|}
\hline-.27 & $.56 * *$ & -.06 & .02 & .35 & .36 \\
\hline .05 & .04 & .04 & .30 & .16 & .13 \\
\hline
\end{tabular}

15 months 
Symbolic play

12 months

15 months

\section{8 months}

Productive language, 24 months

CDI

BSID

Note. Correlation coefficients, which were different in the FR and control group according to difference test based on Fisher's z-transformed correlation coefficients (McNemar, 1969), are marked with bold.

a) Number of subjects varied due to missing data in single measures: $n=27-31$.

\section{.32}

$\begin{array}{llll}.23 & .60 * * * & .52 * * & .44 * \\ .50 * * & .37 * & .28 & .26 \\ & .27 & .37 * & .17\end{array}$

$.71 * * * \quad .24$

$.60 * * *$ 
Table 4. Summary of Hierarchical Regression analysis for predicting productive and receptive language at 2 years of age in children at family risk of dyslexia $(n=26)$

\begin{tabular}{ccccc}
\multicolumn{2}{c}{ Productive Language } & & \multicolumn{2}{c}{ Receptive Language } \\
& $\Delta \mathrm{R}^{2}$ & & 8 & $\Delta \mathrm{R}^{2}$
\end{tabular}

\section{Step 1 (age 12 months)}

Symbolic play

Play

Step 2 (age 15 months)

Early gestures

Step 3 (age 18 months)

$R^{2}$

Note. 6 =standardized regression coefficient.

$* p<.05, * * p<.01, * * * p<.001$
.41

$.14 * *$

ns
$.36 * * *$

$.11^{*}$

$61 * * *$
.44

ns

ns

ns

$.19 *$ 
